\title{
Pengaruh Dukungan Sosial Terhadap Kecemasan Pada Ibu Hamil di Puskesmas Jetis Kabupaten Ponorogo
}

\author{
Ambika Kurnia Mustikawati \\ Akbid Harapan Mulya Ponorogo
}

\begin{abstract}
Background: Pregnancy is a valuable thing, but also one of the great stresses for a woman both physically and mentally. Pregnant women with high anxiety will increase the risk of hypertension, difficulty sleeping and stroke, seizures and even death in the mother and fetus. In Puskesmas Ponorogo district the number of pregnant women as much as 5903 mothers, while in health centers Jetis the number of pregnant women as many as 200 mothers. Interview results, 21 out of 27 mothers said were very anxious during her pregnancy. The purpose of this study was to analyze the factors of social support for anxiety in pregnant women.

Subjects and Methods: The type of research is analytical with cross-sectional approach. The location of research at Jetis health center Ponorogo regency. Research conducted on September 1 to October 15, 2016. Sample of 30 pregnant women using proportional random sampling technique. Dependent variable is anxiety, while independent variable is social support. Data collection techniques using questionnaires. Data analysis using Spearman's Rho using SPSS 18.0 for windows computer program.

Results: The results showed that from 40 respondents, almost half were $13(32.5 \%)$ multiparous had mild anxiety and nearly half were $13(32.5 \%)$ primipara experienced moderate anxiety. of the 40 respondents, nearly half (12\%) of 3 trimester pregnant women had moderate anxiety and a small proportion of $9(22.5 \%)$ of 2 trimester pregnant women had mild anxiety. The result of calculation using spearman's rho statistic test obtained $\mathrm{p}=0,006<\alpha 0,05$ mean there is influence between parity with anxiety in pregnant woman with correlation coefficient of $-0,424$ which show intensity of influence of medium that is if the smaller parity hence more anxiety level. The calculation of gestational age with spearman's rho $p=0,023<\alpha 0.05$ means that there is an influence between parity with anxiety in pregnant women with a correlation coefficient of 0.359 which shows the weakness of weak influence.

Conclusion: The social support provided by husband and family will affect the level of anxiety in each pregnant woman. It is hoped for a place of research to provide a solution for pregnant women who experience anxiety so that pregnancy can run smoothly and respondents are expected to have a good coping mechanism in the face of anxiety for health and also the fetus.
\end{abstract}

Keywords: social support, anxiety, pregnant women

\section{PENDAHULUAN}

Kehamilan tidak hanya masa sukacita yang besar, tetapi juga salah satu stress besar untuk seorang wanita baik secara fisik maupun mental. Bahkan pada wanita yang sehat, kehamilan dapat menimbulkan banyak kecemasan (M. Rauchfuss, 2011). Prevalensi bervariasi dari kecemasan kehamilan pada trimester berbeda dari kehamilan dengan tingkat tinggi pada trimester pertama dan ketiga (Madhavanprabhakaran, 2015). Pada masa ini wanita hamil mengalami kecemasan yang berakibat munculnya depresi dan kesulitan tidur (Wahyuni dan Nida, 2010).

Kecemasan sering kali mengganggu tidur. Seseorang yang pikirannya dipenuhi dengan masalah pribadi dan merasa sulit untuk rileks saat akan memulai tidur. Kecemasan meningkatkan kadar norepinefrin dalam darah melalui stimulasi sistem saraf simpatis (Kozier et al, 2010). 
Data statistik mencatat angka kematian ibu dalam kehamilan dan persalinan mencapai 515.000 jiwa setiap tahun, 99\% terjadi di Negara-negara berkembang. Di Negara miskin, sekitar 20-50\% kematian usia subur disebabkan hal yang berkaitan dengan kehamilan. Prevalensi tingkat kecemasan wanita hamil di Portugal (18,2\%), Bangladesh (29\%), Hongkong (54\%) dan Pakistan (70\%) (WHO, 2013).

Angka Kematian Ibu (AKI) di provinsi Jawa Timur sudah berada dibawah target Millenium Development Goals (MDGs) 2015 sebesar 102 kematian ibu per 100.000 kelahiran hidup. Secara rinci, data laporan kematian ibu Dinkes Kabupaten/ Kota melaporkan tahun 2011 sebesar 101,4 per 100.000 kelahiran hidup, pada tahun 2012 sebesar 97,43 per kelahiran hidup dan pada tahun 2013 sebesar 97,39 per 100.000 kelahiran hidup (SDKI, 2013).

Data dari Dinas Kesehatan Ponorogo Tahun 2016 bulan Januari sampai Juli sebanyak 5903 ibu disajikan dalam tabel dibawah ini:

Tabel 1 Data Ibu Hamil Tahun 2016 Januari sampai Juli 2016

\begin{tabular}{|ll|c|}
\hline No & $\begin{array}{c}\text { Nama } \\
\text { Puskesmas }\end{array}$ & $\begin{array}{c}\text { Jumlah Ibu } \\
\text { Hamil }\end{array}$ \\
\hline 1 & Badegan & 217 \\
2 & Jambon & 281 \\
3 & Sampung & 161 \\
4 & Kunti & 84 \\
5 & Sukorejo & 363 \\
6 & Jenangan & 188 \\
7 & Setono & 135 \\
8 & Balong & 292 \\
9 & Slahung & 170 \\
10 & Nailan & 161 \\
11 & Ngrayun & 343 \\
12 & Bungkal & 250 \\
13 & Jetis & 200 \\
14 & Siman & 148 \\
15 & Ronowijayan & 159 \\
16 & PO. Utara & 290 \\
17 & PO. Selatan & 238 \\
18 & Babadan & 271 \\
19 & Sukosari & 158 \\
20 & Kauman & 192 \\
21 & Ngrandu & 62 \\
22 & Mlarak & 258
\end{tabular}

\begin{tabular}{|ll|c|}
23 & Sambit & 106 \\
24 & Wringinanom & 126 \\
25 & Sawoo & 392 \\
26 & Bondrang & 56 \\
27 & Sooko & 128 \\
28 & Pudak & 56 \\
29 & Pulung & 186 \\
30 & Kesugihan & 123 \\
31 & Ngebel & 109 \\
\hline & JUMLAH & 5903 \\
\hline
\end{tabular}

Berdasarkan studi pendahuluan yang dilakukan pada tanggal 9 Juni 2016 di Puskesmas Jetis Kabupaten Ponorogo didapatkan data jumlah ibu hamil 200 orang. Kemudian diambil secara acak, dari hasil wawancara dengan ibu hamil didapatkan 3 dari 5 orang mengatakan sangat cemas selama kehamilan ini. Hal ini dapat dikatakan bahwa masih banyak ibu hamil yang mengalami kecemasan selama kehamilan.

Penyebab kecemasan antara lain adanya ancaman terhadap tubuh, jiwa atau psikisnya, perentangan karena danya dua keinginan yang keadaannya bertolak belakang, kebutuhan yang tidak terpenuhi dan bila gagal untuk memenuhinya maka timbullah kecemasan, misalnya ketakutan akan kegagalan dalam menghadapi persalian (Sulistyawati, 2012).

Bukti menunjukkan bahwa kehamian dengan kecemasan tidak hanya mempengaruhi kesehatan ibu hamil, tetapi dapat mengakibatkan kelahiran premature, persalinan lama, kelahiran SC dan berat badan lahir rendah (M. Rauchfuss, 2011).

Solusi ibu hamil yang mengalami kecemasan diantaranya meyakinkan pada ibu kalau semuanya akan baik-baik saja. Karena pada ibu yang mengalami kecemasan akan meningkatkan hormon adrenalin dan noradrenalin, atau epinefrin dan norepinefrin menimbulkan disregulasi biokimia tubuh, sehingga muncul ketegangan fisik pada diri ibu hamil. Mengurangi faktor penyebab kecemasan pada ibu hamil sangat penting untuk menurunkan kecemasan dan gangguan tidur, untuk itu peran 
sebagai tenaga kesehatan sangat diperlukan (Kristanto, 2012).

Berdasarkan latar belakang diatas peneliti tertarik melakukan penelitian untuk mengetahui pengaruh dukungan sosial terhadap kecemasan pada ibu hamil di Kabupaten Ponorogo.

Tujuan penelitian ini adalah untuk mengetahui determinan pengaruh kecemasan dan gangguan tidur pada ibu hamil.

\section{TINJAUAN PUSTAKA \\ Konsep Kecemasan}

Kecemasan adalah keadaan emosi negatif yang kuat yang disertai dengan kegelisahan, kekhawatiran, dan pikiran mengganggu yang tidak diinginkan. khawatir, atau keprihatinan atas peristiwa masa depan. Misalnya, seorang wanita hamil dengan tingkat kekhawatiran tentang kesehatan bayinya mungkin cenderung untuk mencari saran medis lebih sering dan terlibat dalam mempromosikan kesehatan perilaku dengan mengkonsumsi vitamin dan makan sehat. Namun, jika dia merasa bahwa dia tidak bisa mengontrol hasil kehamilannya atau tidak dapat mengatasi kecemasan, emosi dapat menjadi bermasalah (Taylor $\mathrm{G}$ et al, 2014).

Penyebab kecemasan diantaranya yaitu :

\section{a. Alkohol}

Kecemasan dan depresi dapat disebabkan oleh penyalahgunaan alkohol, yang dalam banyak kasus membaik dengan pantang berkepanjangan (Bankole, 2011).

$$
\text { Konsumsi kafein dapat }
$$
menyebabkan atau memperburuk gangguan kecemasan. Sejumlah studi klinis telah menunjukkan hubungan positif antara kafein dan efek anxiogenic dan / atau gangguan panik (MM Vilarim, 2011).

b. Kondisi medis

Gangguan kecemasan mungkin efek samping dari penyakit endokrin yang mendasari yang menyebabkan sistem hiperaktivitas saraf, seperti pheochromocytoma atau hipertiroidisme (Kantorovich, 2008).

c. Stres (Tekanan)

Gangguan kecemasan dapat timbul dalam menanggapi tekanan kehidupan seperti kekhawatiran keuangan atau penyakit fisik kronis. Kecemasan di kalangan remaja dan dewasa muda adalah umum karena tekanan interaksi sosial, evaluasi, dan citra tubuh. Kecemasan juga umum di antara orang tua yang memiliki demensia (J Calleo, 2008).

d. Genetika

GAD (General Anxiety Disorder) berjalan dalam keluarga dan enam kali lebih sering terjadi pada anak-anak dari seseorang dengan kondisi tersebut ( $G$ Patel, 2013). Orang dengan gangguan ini memiliki sistem yang sangat sensitif, oleh karena itu, sistem mereka cenderung bereaksi berlebihan terhadap rangsangan yang tampaknya tidak berbahaya.

Kadang gangguan kecemasan terjadi pada mereka yang memiliki pemuda traumatis, menunjukkan peningkatan prevalensi kecemasan ketika muncul seorang anak akan memiliki masa depan yang sulit. Dalam kasus ini, gangguan tersebut timbul sebagai cara untuk memprediksi bahwa lingkungan individu akan terus berpose ancaman (Bandelow et al, 2013).

Pilihan perawatan kecemasan yang tersedia termasuk perubahan gaya hidup, terapi, dan obat-obatan. Obat hanya dianjurkan jika langkah-langkah lain tidak efektif. Berhenti merokok memiliki manfaat dalam kecemasan besar seperti atau lebih besar daripada obat-obatan. Mengurangi asupan kafein dan olahraga teratur juga langkahlangkah yang berguna (G Taylor, 2014).

Olahraga teratur sering berguna dalam mengobati kecemasan. Sebuah study pada tahun 2006 menemukan manfaat kecil tentang latihan untuk kegelisahan pada anak-anak. Ada bukti bahwa yoga dan meditasi mungkin efektif dalam mengurangi kecemasan 
(Li, AW and Goldsmith, 2012). Aromaterapi telah menunjukkan beberapa manfaat untuk pengurangan kecemasan pada orang karena pengaruh relaksasinya (Co Mi Yeon, et al, 2013).

Dukungan merupakan salah satu faktor yang dapat membantu anak dalam mengadapi stressor. Wills cit Friedman menyatakan bahwa dukungan keluarga dapat menimbulkan efek penyangga yaitu dukungan keluarga menahan efekefek negatif dari stres terhadap kesehatan dan efek utama yaitu dukungan keluarga secara langsung mempengaruhi peningkatan kesehatan (Hu H et al, 2015).

Olahraga teratur sering berguna dalam mengobati kecemasan. Sebuah study pada tahun 2006 menemukan manfaat kecil tentang latihan untuk kegelisahan pada anak-anak. Ada bukti bahwa yoga dan meditasi mungkin efektif dalam mengurangi kecemasan (Li, AW and Goldsmith, 2012). Aromaterapi telah menunjukkan beberapa manfaat untuk pengurangan kecemasan pada orang karena pengaruh relaksasinya (Co Mi Yeon, et al, 2013).

Dukungan keluarga merupakan salah satu faktor yang dapat membantu anak dalam mengadapi stressor. Wills cit Friedman menyatakan bahwa dukungan keluarga dapat menimbulkan efek penyangga yaitu dukungan keluarga menahan efek-efek negatif dari stres terhadap kesehatan dan efek utama yaitu dukungan keluarga secara langsung mempengaruhi peningkatan kesehatan (Hu H et al, 2015).

\section{Konsep Kecemasan dalam Kehamilan}

Kecemasan pada kehamilan adalah keadaan emosi yang mirip dengan kecemasan pada umumnya namun berbeda karena secara khusus berakar pada keprihatinan pada wanita hamil dalam konteks kehamilan mereka. Kecemasan kehamilan sebagai keadaan emosi negatif yang terkait dengan kekhawatiran tentang "kesehatan dan kesejahteraan seseorang bayi, siapa yang membantu melahirkan, rumah sakit dan pengalaman perawatan kesehatan (termasuk seseorang kesehatan sendiri dan kelangsungan hidup pada kehamilan), kelahiran dan postpartum, dan peran orang tua atau ibu (Dunkel Schetter, 2011).

Kecemasan kehamilan dalam beberapa tahun terakhir ini dapat dilihat dari temuan penelitian yang menghubungkan dengan kelahiran prematur. Kelahiran prematur terjadi sebelum 37 minggu gestasi. Sebuah $12 \%$ dari bayi yang lahir di US dilahirkan preterm, dan tingkat prematur kelahiran yang tinggi di US dibandingkan dengan lain yang patut negara-negara maju. Ada juga permasalahan ras, etnis, dan kesenjangan sosial ekonomi di tingkat pra lahir. lahir. Misalnya, sekitar 17\% kelahiran antara Afrika-Wome Amerika pada tahun 2011 yang prematur, sedangkan tingkat untuk perempuan kulit putih adalah $10,5 \%$. Hasil dari multi studi berbasis komunitas etnis besar di Amsterdam yang melibatkan 7740 wanita hamil mengungkapkan bahwa kehamilan kecemasan terkait dengan hasil kerja yang merugikan seperti prematur dan berat badan lahir rendah (Dijk, et al., 2013). Perbedaan ini terutama menyangkut karena hasil kelahiran prematur secara lebih risiko kesehatan bagi bayi dan sering membawa biaya emosional dan finansial yang luar biasa untuk keluarga (Hamilton et al., 2013).

Adapun karakteristik ibu hamil yang mempengaruhi kecemasan dalam menghadapi persalinan antara lain:

a. Umur

WHO memberikan rekomendasi umur yang dianggap paling aman menjalani kehamilan dan persalinan adalah 20-35 tahun. Di rentang usia ini kondisi fisik wanita dalam keadaan prima. Rahim sudah mampu memberi perlindungan, mental pun siap untuk merawat dan menjaga kehamilannya secara hati-hati.

Kehamilan di umur kurang dari 20 tahun bisa menimbulkan masalah, karena kondisi fisik belum $100 \%$ 
siap. Beberapa resiko yang bisa terjadi pada kehamilan di umur ini adalah kecenderungan naiknya tekanan darah dan pertumbuhan janin terhambat. Di luar urusan kehamilan dan persalinan, resiko kanker leher rahim pun meningkat akibat hubungan seks dan melahirkan. Sedangkan setelah umur 35 tahun, sebagian wanita digolongkan pada kehamilan beresiko tinggi terhadap kelainan bawaan dan adanya penyulit pada waktu persalinan. Di kurun umur ini, angka kematian ibu melahirkan dan bayi meningkat (Tobing, 2007).

b. Paritas

Paritas adalah banyaknya kelahiran hidup yang dipunyai oleh seorang wanita (BKKBN, 2006). Primipara adalah wanita yang telah melahirkan seorang anak, yang cukup besar untuk hidup di dunia luar (Varney, 2006). Sedangkan multipara adalah wanita yang telah melahirkan seorang anak lebih dari satu kali (Prawirohardjo, 2009).

Ibu akan cenderung merasa cemas dengan kehamilannya, merasa gelisah, dan takut menghadapi persalinan, mengingat ketidaktahuan menjadi faktor penunjang terjadinya kecemasan. Bagi primipara, kehamilan yang dialaminya merupakan pengalaman pertama kali, sehingga trimester III dirasakan semakin mencemaskan karena semakin dekat dengan proses persalinan. Ibu akan cenderung merasa cemas dengan kehamilannya, merasa gelisah, dan takut menghadapi persalinan, mengingat ketidaktahuan menjadi faktor penunjang terjadinya kecemasan. Sedangkan ibu yang pernah hamil sebelumnya (multigravida), mungkin kecemasan berhubungan dengan pengalaman masa lalu yang pernah dialaminya (Zamriati, 2013).

c. Tingkat Pendidikan

Pendidikan merupakan kebutuhan dasar manusia yang sangat dibutuhkan untuk pengembangan diri dan peningkatan kematangan intelektual seseorang. Tingkat pendidikan juga merupakan salah satu faktor yang mempengaruhi persepsi seseorang untuk lebih mudah menerima ide teknologi baru (Notoatmodjo, 2003).

Semakin tinggi pendidikan seseorang, maka akan semakin berkualitas pengetahuannya dan semakin matang intelektualnya. Semakin tinggi tingkat pendidikan seseorang semakin besar peluang untuk mencari pengobatan ke pelayanan kesehatan. Sebaliknya rendahnya pendidikan akan menyebabkan seseorang mengalami stres, dimana stres dan kecemasan yang terjadi disebabkan kurangnya informasi yang didapatkan orang tersebut.

d. Pekerjaan

\begin{tabular}{llr}
\multicolumn{2}{c}{ Pekerjaan } & adalah \\
kesibukan & yang & dilakukan \\
seseorang & terutama & untuk \\
menunjang & kehidupannya dan \\
keluarganya & \multicolumn{2}{r}{ sehingga }
\end{tabular}

keluarganya
menghasilkan suatu penghasilan berupa uang (Narbuko, 2002). Pekerjaan dapat menghasilkan penghasilan yang akan menambah keuangan keluarga, sehingga ibu hamil benar-benar siap untuk menghadapi persalinannya nanti. Seorang ibu dapat mengetahui semua informasi kesehatan mengenai dirinya dan bayi yang ada dalam kandungannya, sehingga dapat menjalani kehamilan yang aman dan menyenangkan, serta mencegah timbulnya kecemasan.

e. Status Kesehatan

Pemeliharaan dan pelayanan kesehatan dapat terjamin. Seorang ibu dapat mengetahui semua informasi kesehatan mengenai dirinya dan bayi yang ada dalam kandungannya, sehingga dapat menjalani kehamilan yang aman dan menyenangkan, serta mencegah timbulnya kecemasan.

f. Dukungan Sosial 
Dukungan sosial merupakan bantuan atau dukungan yang diterima individu dari orang-orang tertentu dalam kehidupannya dan berada dalam lingkungan sosial tertentu lingkungan sosial tertentu seperti suami, orangtua, mertua, teman atau tetangga yang membuat penerima merasa diperhatikan, dihargai dan dicintai sedang-kan untuk orang yang menerima dukungan sosial memahami makna dukungan sosial yang diberikan oleh orang lain.

Dukungan keluarga

terutama dari suami merupakan faktor utama yang berpengaruh terhadap terjadinya kecemasan pada ibu hamil dalam menghadapi masa kehamilan sampai persalinan. Beberapa bentuk dukungan suami yang sangat dibutuhkan oleh ibu hamil antara lain, pelayanan yang baik, menyediakan transportasi atau dana untuk biaya konsultasi, dan menemani berkonsultasi ke dokter ataupun bidan sehingga suami dapat mengenali tanda-tanda komplikasi kehamilan dan juga kebutuhan ibu hamil (Asrinah, 2010).

\section{METODE PENELITIAN}

Penelitian ini termasuk penelitian ex post facto. Lokasi penelitian di wilayah kerja Puskesmas Jetis Kabupaten Ponorogo. Penelitian ini dilaksanakan pada 01 September - 15 Oktober 2016. Populasi 200 ibu hamil yang mengalami kecemasan. Sampel sebanyak 30 dengan menggunakan teknik fixed exposure sampling. Teknik pengumpulan data menggunakan kuisioner.

Definisi operasional dalam penelitian ini yaitu:

a. Dukungan sosial

Dukungan sosial adalah dukungan dari suami, orang tua, saudara, mertua, teman, tetangga, orang terdekat dalam bentuk membantu atau memberikan perhatian kepada ibu hamil yang mengalami kecemasan. Dukungan keluarga tersebut diberikan dengan cara keluarga menunjukan kepedulian, perhatian, memahami, memberikan semangat, dan menghiburnya apabila sedang mengalami kecemasan. Dukungan sosial menggunakan alat ukur kuesioner dengan 10 pertanyaan, dinilai dengan skala likert. Pernyataan yang digunakan dalam skala ini meliputi pernyataan favourable dan unfavourable. Untuk penyataan favourable diberi nilai 0 apabila tidak pernah, nilai 1 apabila kadang-kadang, nilai 2 apabila sering, dan nilai 3 apabila selalu. Untuk pernyataan unfavourable diberi nilai 3 apabila tidak pernah, nilai 2 apabila kadang-kadang, nilai 1 apabila sering, dan nilai 0 apabila selalu. Kriteria dari dukungan keluarga yaitu apabila jumlah nilai $\geq 25$ maka keluarga mendukung, sedangkan apabila nilainya $<25$ maka keluarga dianggap tidak mendukung.

b. Kecemasan

Kecemasan kehamilan merupakan keadaan emosi negatif yang terkait dengan kekhawatiran tentang "kesehatan dan kesejahteraan seseorang bayi, siapa yang membantu melahirkan, rumah sakit dan pengalaman perawatan kesehatan (termasuk seseorang kesehatan sendiri dan kelangsungan hidup pada kehamilan), kelahiran dan postpartum, dan peran orang tua atau ibu. Kecemasan menggunakan alat ukur HARS (Hamilton Anxiety Rating Scale). Skala HARS terdapat 14 syptoms yang nampak pada individu yang mengalami kecemasan. Dinilai dengan skala likert: diberi nilai $0=$ tidak ada gejala sama sekali, 1 = Satu dari gejala yang ada, 2 =sedang/ separuh dari gejala yang ada, $3=$ berat/lebih dari setengah gejala yanada, $4=$ sangat berat semua gejala ada. Penentuan derajat kecemasan dengan cara menjumlah nilai skor dan item 1-14 dengan hasil: 
1) Skor kurang dari $6=$ tidak ada kecemasan

2) Skor $7-14=$ kecemasan ringan

3) Skor $15-27=$ kecemasan sedang

4) Skor lebih dari $27=$ kecemasan berat

Analisis data menggunakan Spearman's rank dengan bantuan program komputer yaitu SPSS 18.0 for Windows pada taraf signifikan 0,05 . Jika $\mathrm{p}<\alpha 0.05 \mathrm{H} 0$ ditolak dan jika $\mathrm{p}>\alpha 0.05$ $\mathrm{H} 0$ diterima.

\section{HASIL PENELITIAN}

1. Dukungan Sosial Ibu Hamil

Tabel 2 Distribusi Frekuensi

Dukungan Sosial Ibu Hamil di

Puskesmas Jetis Tahun 2016

\begin{tabular}{|c|c|c|}
\hline Kriteria & Frekuensi & $\begin{array}{c}\text { Persen } \\
(\%)\end{array}$ \\
\hline Mendukung & 24 & 80.0 \\
Tidak Mendukung & 6 & 20.0 \\
\hline Total & 30 & 100.0 \\
\hline
\end{tabular}

Sumber : Kuesioner

Berdasarkan tabel diatas menunjukkan bahwa hampir seluruhnya yaitu sebanyak 24 responden $(80 \%)$ ibu hamil mendapatkan dukungan sosial, sebagian kecil sebanyak 6 responden (20\%) ibu hamil tidak mendapatkan dukungan sosial.

2. Kecemasan Ibu Hamil

Tabel 3 Distribusi Frekuensi Kecemasan Ibu Hamil di Puskesmas Jetis Tahun 2016

\begin{tabular}{|l|c|c|}
\hline \multicolumn{1}{|c|}{ Kriteria } & Frekuensi & $\begin{array}{c}\text { Persen } \\
(\%)\end{array}$ \\
\hline Tidak Cemas & 11 & 36.7 \\
Kecemasan Ringan & 12 & 40.0 \\
Kecemasan Sedang & 7 & 23.3 \\
Kecemasan Berat & 0 & 0 \\
\hline Total & 30 & 100.0 \\
\hline
\end{tabular}

Sumber : Kuesioner
Berdasarkan tabel diatas menunjukkan bahwa hampir setengahnya responden yaitu sebanyak $12 \quad(40,0 \%)$ mengalami kecemasan ringan, hampir setengahnya responden yaitu sebanyak $11 \quad(36,7 \%)$ tidak mengalami kecemasan, sebagian kecil yaitu sebanyak $7 \quad(23,3 \%)$ mengalami kecemasan sedang dan tidak satupun $(0 \%)$ responden mengalami kecemasan berat.

3. Tabulasi Silang Dukungan Sosial Terhadap Kecemasan Pada Ibu Hamil

di Puskemas Jetis

\begin{tabular}{|c|c|c|c|c|c|}
\hline \multirow{2}{*}{$\begin{array}{c}\text { Dukungan } \\
\text { Sosial }\end{array}$} & $\begin{array}{c}\text { Tidak } \\
\text { ada }\end{array}$ & Ringan & Sedang & Berat & Total \\
\cline { 3 - 5 } Mendukung & 11 & 12 & 1 & 0 & 24 \\
$\begin{array}{c}\text { Tidak } \\
\text { mendukung } \\
\text { Total }\end{array}$ & 0 & 0 & 6 & 0 & 6 \\
\hline
\end{tabular}

Sumber : Kuesioner

Berdasarkan tabel 4 menunjukkan bahwa dari $24 \mathrm{ibu}$ hamil yang mendapatkan dukungan sosial 11 responden diantaranya tidak mengalami kecemasan, 12 responden diantaranya mengalami kecemasan ringan dan 1 responden diantaranya mengalami kecemasan sedang. Ibu hamil yang tidak mendapatkan dukungan sosial yaitu sebanyak 6 responden seluruhnya mengalami kecemasan sedang.

4. Uji Statistik Dukungan Sosial Terhadap Kecemasan Pada Ibu Hamil

Tabel 5 pengaruh dukungan sosial terhadap kecemasan pada ibu hamil 


\begin{tabular}{|lll|r|r|}
\hline & & Dukungan sosial & Kecemasan \\
\hline Spearman's rho Dukungan & Correlation Coefficient & 1.000 & .710 \\
& sosial & Sig. (2-tailed) &. & .000 \\
& $\mathrm{~N}$ & 30 & 30 \\
\cline { 2 - 5 } & Kecemasan & Correlation Coefficient & $.710^{* *}$ & 1.000 \\
& Sig. (2-tailed) & .000 & \\
& $\mathrm{~N}$ & 30 & 30 \\
\hline
\end{tabular}

Berdasarkan tabel 5 diatas dengan hasil perhitungan menggunakan uji statistik spearman's rho dengan taraf signifikan 0,05 yaitu $\mathrm{p}=0,000<\alpha 0,05$ artinya Ho ditolak dan $\mathrm{H} 1$ diterima, sehingga ada pengaruh antara dukungan sosial dengan kecemasan pada ibu hamil di Puskesmas Jetis dengan koefisien korelasi $-0,710$ yang menunjukkan keeratan pengaruh yang tinggi yaitu apabila semakin besar dukungan keluarga maka tingkat kecemasan berkurang.

\section{PEMBAHASAN}

\section{Dukungan Sosial Ibu Hamil}

Berdasarkan penelitian yang dilakukan didapatkan bahwa hampir seluruhnya yaitu sebanyak 24 responden $(80 \%)$ ibu hamil mendapatkan dukungan sosial, sebagian kecil sebanyak 6 responden (20\%) ibu hamil tidak mendapatkan dukungan sosial.

Dukungan sosial merupakan bantuan atau dukungan yang diterima individu dari orang-orang tertentu dalam kehidupannya dan berada dalam lingkungan sosial tertentu dan berada dalam lingkungan sosial tertentu seperti suami, orangtua, mertua, teman atau tetangga yang membuat penerima merasa diperhatikan, dihargai dan dicintai sedang-kan untuk orang yang menerima dukungan sosial
Dukungan sosial sangat dibutuhkan bagi ibu hamil terlebih dalam menjelang masa persalinan tiba. Dukungan sosial bukan sekedar memberikan bantuan, tetapi yang penting adalah bagaimana persepsi si penerima terhadap makna dari bantuan itu. Hal itu erat hubungannya dengan ketepatan dukungan sosial yang diberikan, dalam arti bahwa orang yang menerima sangat merasakan manfaat ban-tuan bagi dirinya, karena sesuatu yang aktual dan memberikan kepuasan (Whalley, 2008).

Dukungan keluarga terutama dari suami merupakan faktor utama yang berpengaruh terhadap terjadinya kecemasan pada ibu hamil dalam menghadapi masa kehamilan sampai persalinan. Beberapa bentuk dukungan suami yang sangat dibutuhkan oleh ibu hamil antara lain, pelayanan yang baik, menyediakan transportasi atau dana untuk biaya konsultasi, dan menemani berkonsultasi ke dokter ataupun bidan sehingga suami dapat mengenali tanda-tanda komplikasi kehamilan dan juga kebutuhan ibu hamil (Asrinah, 2010).

Suami dan keluarag sebaiknya menemani istri terutama pada masa kehamilan trimester ketiga ibu hamil mengalami kecemasan dalam menanti persalinan yang akan terjadi dalam waktu dekat. Suami yang tidak dapat menemani istrinya yang sedang 
hamil akan berdampak pada kondisi ibu hamil itu sendiri, ibu hamil akan merasa takut, tidak adanya rasa aman dan nyaman, dan tidak ada yang memberikan dorongan kepada istri karena suami merupakan orang pertama dan utama yang dapat memberikan support dan ketenangan batin dan perasaan senang dalam diri istri.

\section{Kecemasan Pada Ibu Hamil}

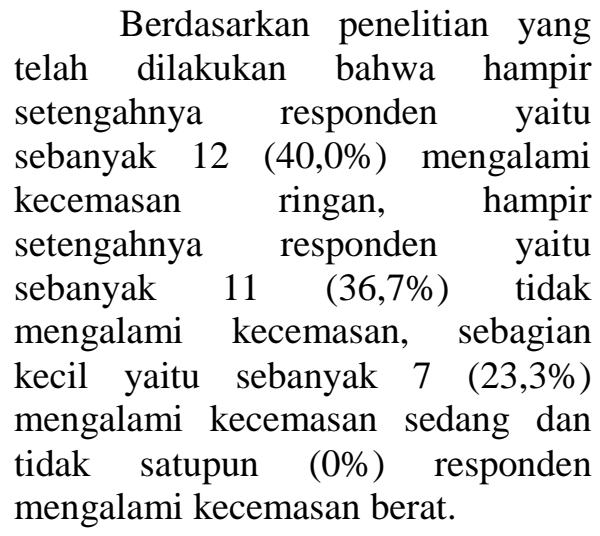

Kecemasan pada kehamilan dapat dianggap sebagai interaksi antara umum wanita predisposisi ke arah cemas emosional dan kondisi kehamilannya. Kondisi tersebut meliputi risiko medis, kondisi seperti hipertensi yang mungkin mempengaruhi hasil kehamilan, riwayat komplikasi pada kehamilan sebelumnya atau kelahiran, dan juga faktor psikososial seperti apakah kehamilannya direncanakan atau tidak, kurangnya perawatan prenatal, dukungan sosial yang tersedia, rendah pendapatan, dan kurangnya sumber daya lainnya. Misalnya, wanita dengan tingkat kecemasan tinggi mungkin sangat waspada selama kehamilan dan cenderung untuk menafsirkan hal yang tidak pasti, seperti hasil tes tidak meyakinkan atau tubuh seperti sensasi kram, sebagai ancaman (Hamilton et al., 2013).
Disisi lain, situasi tertentu seperti kondisi medis berisiko tinggi atau tidak diinginkannya kehamilan dengan dukungan memadai dari ayah bayi dapat mengancam untuk menginduksi kecemasan bahkan di antara wanita yang tidak biasanya cemas. Terlepas dari asal kecemasan selama kehamilan telah terbukti menimbulkan risiko atas dan di luar menderita penyakit medis dan faktor risiko tradisi (Hamilton et al., 2013).

Hasil penelitian ini mendukung hasil penelitian yang dilakukan oleh Cole L (2014) dengan judul "pregnancy specific stress, preterm birth and gestasional age among high risk young women" menyimpulkan bahwa hubungan kehamilan dengan stress secara spesifik penyebab terjadinya keguguran pada kehamilan usia muda (trimester 1). Sedangkan untuk trimester 2 dan trimester 3 hubungan kehamilan dengan stress jarang berpengaruh terhadap kematian janin. Pada trimester 3 hubungan kehamilan dengan spesifik stress terjadi ketika akan menghadapi persalinan untuk itu diperlukan manajemen stress yang baik agar persalinan berjalan lancar.

Perubahan psikologis ibu hamil pada tiap trimester mempengaruhi hormone yang ada didalam tubuhnya dab hal ini juga membuat ibu hamil merasa cemas. Perubahan emosional pada akhir trimester 3 biasanya gembira bercampur takut karena kehamilan telah mendekati persalinan dan hal ini menambah timbul rasa kecemasan yang dialami.

\section{Pengaruh Dukungan Sosial Terhadap Kecemasan Ibu Hamil}

Hasil perhitungan menggunakan uji statistik spearman's rho dengan taraf signifikan 0,05 yaitu $\mathrm{p}=0,000<$ a 0,05 artinya Ho ditolak dan $\mathrm{H} 1$ diterima, sehingga ada pengaruh 
antara dukungan sosial dengan kecemasan pada ibu hamil di Puskesmas Jetis dengan koefisien korelasi -0,710 yang menunjukkan keeratan pengaruh yang tinggi.

Hasil tabulasi silang menunjukkan bahwa dari 24 ibu hamil yang mendapatkan dukungan sosial 11 responden diantaranya tidak mengalami kecemasan, 12 responden diantaranya mengalami kecemasan ringan dan 1 responden diantaranya mengalami kecemasan sedang. Ibu hamil yang tidak mendapatkan dukungan sosial yaitu sebanyak 6 responden seluruhnya mengalami kecemasan sedang.

Dukungan sosial sangat dibutuhkan bagi ibu hamil terlebih dalam menjelang masa persalinan tiba. Dukungan sosial bukan sekedar memberikan bantuan, tetapi yang penting adalah bagaimana persepsi si penerima terhadap makna dari bantuan itu. Hal itu erat hubungannya dengan ketepatan dukungan sosial yang diberikan, dalam arti bahwa orang yang menerima sangat merasakan manfaat ban-tuan bagi dirinya, karena sesuatu yang aktual dan memberikan kepuasan (Whalley, 2008).

Hasil penelitian yang dilakukan oleh Madhavanprabhakaran (2015) yang berjudul "Prevalence of pregnancy anxiety and associated factors" menyimpulkan bahwa dukungan keluarga yang baik dan keharmonisan perkawinan wanita hamil di Kerala, India dilaporkan tinggi. Hal ini mampu menurunkan prevalensi kecemasan selama hamil terutama ketika akan menghadapi persalinan. Tingginya prevalensi kecemasan kehamilan dapat dikaitkan dengan rendahnya pengetahuan tentang melahirkan dan mengasuh anak karena kurangnya pendidikan formal tentang melahirkan di era norma keluarga inti. Para penulis merekomendasikan pendidikan formal tentang melahirkan bagi perempuan hamil di semua rumah sakit di Kerala untuk meningkatkan persiapan melahirkan dan memberdayakan perempuan untuk mengatasi perubahan dan tantangan kehamilan dan kelahiran.

Berdasarkan hal tersebut maka dapat disimpulkan bahwa adanya pengaruh negatif antara dukungan keluarga dan kecemasan secara langsung. Dukungan keluarga sangat diperlukan ibu hamil terutama dari suami. Beberapa bentuk dukungan suami yang dibutuhkan oleh ibu hamil antara lain, pelayanan yang baik, menyediakan transportasi atau dana untuk biaya konsultasi, dan menemani berkonsultasi ke dokter ataupun bidan serta menemani saat persalinan. Kedekatan emosional antara ibu dengan keluarga akan membuat psikologis ibu tenang dan bahagia selama hamil sehingga kehamilan berjalan dengan lancar. Dengan demikian hasil penelitian ini dapat dikatakan sejalan dengan penelitian diatas.

\section{KESIMPULAN DAN SARAN}

a. Kesimpulan

Berdasarkan analisa data penelitian yang telah dilakukan, maka dapat disimpulkan sebagai berikut:

1. Hampir seluruhnya yaitu sebanyak 24 responden $(80 \%)$ ibu hamil mendapatkan dukungan sosial di Puskesmas Jetis Ponorogo.

2. Hampir setengahnya responden yaitu sebanyak $12 \quad(40,0 \%)$ mengalami kecemasan ringan dan hampir setengahnya responden yaitu sebanyak $11(36,7 \%)$ tidak mengalami kecemasan di Puskesmas Jetis Ponorogo.

3. Ada pengaruh antara dukungan sosial terhadap kecemasan pada ibu hamil di Puskesmas Jetis, berdasarkan analisis data $\mathrm{p}=0,000$ $<\alpha 0,05$ artinya Ho ditolak dan H1 diterima, sehingga ada pengaruh antara dukungan sosial 
dengan kecemasan pada ibu hamil di Puskesmas Jetis dengan koefisien korelasi $-0,710$ yang menunjukkan keeratan pengaruh yang tinggi.

b. Saran

1. Bagi Tempat Penelitian

Disarankan pada tempat penelitian agar memberikan konseling kepada keluarga maupun suami dari ibu hamil agar memberikan dukungan selama kehamilan.

2. Bagi Responden

Disarankan responden untuk memiliki mekanisme koping yang baik dalam menghadapi kecemasan untuk kesehatannya dan juga janinnya.

3. Bagi Peneliti selanjutnya

Disarankan peneliti selanjutnya meneliti faktor-faktor atau pengaruh lain yang mempengaruhi kecemasan dan bisa menggunakan metode penelitian yang berbeda sehingga mampu meneliti secara lebih mendalam lagi.

\section{DAFTAR PUSTAKA}

Ada, Y. (2008). Kebisingan, Pencahayaan, dan Getaran di Tempat Kerja. Mitra No. 3 Tahun XIV Desember 2008.

Bobak, I. M., et al. ( 2005). Maternity Nursing. Ed. 4 Mosby Year Book.

Cole L, Kershaw V, Yonkers A, Lin H, Ickovics J. (2014). Pregnancy Specific Stress, Preterm Birth And Gestasional Age Among High Risk Young Women, Health Psychol. NIH Public Access33 (9): 1033-1045. doi: 10.1037/a0034586

Dunkel SC, Lobel M. (2011) . Pregnancy And Birth: A
Multilevel Analysis Of Stress

And Birth Weight. In:

Revenson, T.; Baum, A.;

Singer, J., editors. Handbook

of health psychology 2.

Lawrence Erlbaum; Mahwah, NJ: 2011. p. 427-453.

Huliana,M.2007.Panduan Menghadapi
Kehamilan
Sehat.Jakarta.Puspa Swara

Janiwanty B, Pieter H.Z. (2013). Pendidikan Psikologi Untuk Bidan. Yogyakarta: ANDI

Kizilırmak A, Timur S, and Kartal B, (2012). Insomnia in Pregnancy and Factors Related to Insomnia.

ScientificWorldJournal. 2012; 2012: 197093. Published online 2012 Apr 24. doi: 10.1100/2012/197093 PMCID: PMC3349327

Kristianto (2013). Efektifitas Teknik Relaksasi Nafas Dalam dan Guided Imagery Terhadap Penurunan Nyeri Pada Pasien Post Operasi Sectio Caesarea Di Irina D BLU RSUP Prof.Dr.R.D.Kandou. Manado

Kozier, et al. (2010). Buku Ajar Fundamental Keperawatan: Konsep, Proses Dan Praktik. Jakarta. EGC

Madhavanprabhakaran GK and MS D'Souza, KS. (2015). Prevalence Of Pregnancy Anxiety And Associated Factors. International Journal Of Africa Nursing Sciences Volume 3, 2015, Pages 1-7

M. Rauchfuss, B. (2011). Maier Biopsychosocial Predictors Of Preterm Delivery. Journal of Perinatal 
Medicine, 39 (5) (2011), pp. 515-521

Murti, B. (2013). Desain Dan Ukuran Sampel Untuk Penelitian Kuantitatif Dan Kualitatif Di Bidang Kesehatan. Yogyakarta: Gajah Mada University Press.

Reliabilitas $\quad$ Validitas Dan
Internet Pengukuran.
fk.uns.ac.id/index.php/download
/file/61 Diakses pada tanggal 18
November 2015.

Rukiyah, et al. (2011). Asuhan Kebidanan I (Kehamilan). Jakarta: CV. Trans Info Media

SDKI, (2013). Angka Kematian Ibu

Sulistyawati, Ari.2012.Asuhan Kebidanan pada Masa Kehamilan.Jakarta: Salemba Medika

Ulrike Gehring, Tamburic Lillian, Sbihi Hind, Davies Hugh W, Brauer Michaelb (2014). Impact of Noise and Air Pollution on Pregnancy Outcomes. Epidemiology: May 2014 Volume 25 - Issue 3 - p 351358

doi:

10.1097/EDE.0000000000000 073

Wahyuni, Nida Q. (2010). Pengaruh Senam Hamil Terhadap Perubahan Kadar Hemoglobin (Hb) Pada Kehamilan Trimester Ketiga. Jurnal Kesehatan, 3(2)

Whalley, Janet dkk. 2008.Kehamilan dan Persalinan.Jakarta: PT Bhuana Ilmu Populer.

WHO, (2013). Trend in Maternal Mortality 2013. www.who.int.
Zamriati, Wa Ode. (2013). FaktorFaktor Yang Berhubungan Dengan Kecemasan Ibu Hamil Menjelang Persalinan di Poli KIA PKM Tuminting. ejournal keperawatan (e.Kp) Volume. 1 Nomor. 1 Agustus 2013 
